far into the nineteenth century, when popular magazines tended to replace them. Now they become plentiful again at times of great public excitement. The Oxford pamphlets of 1914-18 are still fresh in the memories of people who have reached or passed middle age. Pamphlets are with us again. They cover many subjects-scientific, geographical, historical, biographical, and all that relates to the Fighting Forces. For the most part they are authoritatively written, and "show the complexion of the times" very effectively.

Recent additions to the Oxford pamphlets (Oxford University Press, 3d. net) include Lieut.-Col. Casson's "Greece", written by one who is both a scholar and a soldier, and describing the character and traditions of the Greek people. Sir John Pratt, writing from an intimate knowledge of the Far East, describes in "Great Britain and China" the chief episodes in our relations with China since 1715, when the East-India Company set up its factory in Canton; and Admiral Sir Herbert Richmond, distinguished alike as naval officer and writer, in his "War at Sea To-day" makes clear to the layman the new difficulties of naval warfare, and the means adopted to meet them.

The latest addition to Federal Tracts, published by Macmillan and Co., Ltd. (6d. net), for Federal Union Research Institute, is Prof. George Catlin's valuable pamphlet on "Anglo-American Union as a Nucleus of World Federation" - a title which explains itself. The author's distinguished record as a student of politics, and as an exponent of this particular subject, marks him out as a high authority. World federation is for him the ultimate aim, but Anglo-American Union is the first step. Cultural autonomy is the due of all nations, even the smallest, but national sovereignty is not. Lord Balfour's reference to "an English-speaking method of looking at the great affairs of mankind" is recalled and enforced-that sense of a common culture which needs to be made more articulate. Prof. Catlin regretfully points out that the whole issue has received far less attention and publicity in Britain than in the United States and the Dominions.

"The Body as a Guide to Politics", by Dr. W. B. Cannon, formerly professor of physiology at Harvard, afterwards of the British Military Service, and later of the U.S.A. Medical Corps, is more directly scientific in tone. His general thesis, which may sound fanciful at first hearing, is that the external and internal relations and activities of the body are so marvellously organized by Nature that they may throw light on the present defects of organization by man. When danger threatens the body, stabilizing agencies act on the instant to guarantee security, but when danger threatens a nation disruptive factors have full sway. The pamphlet is an elaboration of the epilogue to Dr. Cannon's popular work "The Wisdom of the Body", published in 1932. It is included in the series "The Thinker's Forum", published by the Rationalist Press Association. In the same series appears Muriel Jaeger's "Wars of Ideas", expounding the claim that Nazi-ism is a new religion, with Hitler as its Messiah.

\section{Geographical Names}

THE vexed problem of geographical place names is raised again in an article in the Geographical Journal for October in which the Permanent Committee on Geographical Names of the Royal Geographical Society, Kensington Gore, S.W.7, enumerates certain principles which are offered for criticism. The whole memorandum is too long for extensive quotation but some of the main principles may be noted. Generally speaking, names should be those used by the responsible government or official survey of the country concerned, in the case of countries that use a Roman alphabet. In names of features or places in lands not using a Roman alphabet, transliteration, with certain qualifications, is recommended. But exceptions to these general rules are allowed. In popular, text and small-scale maps, English names of conventional usage are allowed; in learned works and large-scale maps conventional English names are allowed for marine features outside territorial limits and features of international interest, with the recommendation that the foreign official name, if it differs markedly from the English, should be given in brackets. Other exceptions are in favour of English or international postal names of important places that differ markedly from official names, and, in historical context, the use, either of the name or narrow transliteration of the name that prevailed at the time under consideration, or the name conventionally known to English scholars. It is emphasized that these principles do not necessarily represent the considered views of the committee but are put forward as a basis for discussion.

\section{Russian Scientific and Technical Periodicals in Great Britain}

ON the recommendation of the Anglo-Soviet Scientific Collaboration Committee, the British Council requested the Association of Special Libraries and Information Bureaux to undertake a survey of the war holdings of Russian scientific and technical periodicals available in Great Britain. The survey, covering the years 1939-42 inclusive, has just been completed, and summaries of the results may be obtained from A.S.L.I.B., 31 Museum Street, London, W.C.1 "Wartime Guides to British Sources of Specialised Information, No.4", $1 s .6 d$. to members of A.S.L.I.B., and $2 s$. $6 d$. to non-members, postage inclusive). More than two hundred specialized libraries participated in the survey, which covers three hundred and thirty-four periodicals. From the summarized results it is possible to tell at a glance whether complete series of each of the periodicals for the last four years may be consulted in the Science Library or Patent Office, whether complete series have been located in other libraries, or whether the series located are incomplete. For further detailed information concerning the location of incomplete sets and odd numbers of periodicals, application should be made to A.S.L.I.B., 'where an index showing the particular issues received, their location, and the conditions of their accessibility is maintained. It is apparent from the survey that very few of the 1942 issues have so far been located, but attention is directed to the considerable time-lag in transit.

\section{Potato Tips as Seed}

The importance of the potato, not only as human and animal food but also as a raw material for the manufacture of starch, alcohol and synthetic rubber, has greatly increased in the U.S.S.R. since the War. At the beginning of the War a big increase in the potato crop was ordered by the Government, but to achieve the goal set, a large addition to the amount of seed potatoes available was necessary. Lyssenko claims that the problem can be, and to some extent already has been, solved by utilizing as seed small pieces of tuber weighing about half an ounce and containing one of the upper eyes. The rest of the 
tuber-about 90 per cent of the whole-can be used as food. It is said that tips yield as well as whole tubers and that their produce is less subject to disease. In 1942, in the U.S.S.R., 250,000 acres were sown with potato tips, and it is anticipated that ten times this area will be thus sown in 1943. This would mean an additional 8 or 9 million tons of potatoes in 1943 without having appreciably reduced the quantity available for food and industry in 1942 .

\section{Methods of Clearing Derelict Land}

THE clearing and reclamation of derelict land has become an urgent problem on many farms in Britain to-day. In view of the recent developments in the mechanization of British agriculture, the new edition of Bulletin No. 101, "Hedge and Tree-Stump Clearing", by T. Swarbrick, recently published by the Ministry of Agriculture (price 6d.), should prove of great help to farmers faced with probably unfamiliar operations. The methods recommended fall into four groups : hand methods, the use of power, chemical agents and explosives. The means selected depends upon a variety of circumstances. Much can be done with timber jacks and monkey winches, especially when isolated trees are the chief problem. If hedges also need removing and no tractor is available, the use of a monkey winch in conjunction with explosives is suggested, for horses can then pull out the small stuff. As regards power methods, the track-laying type of tractor is undoubtedly most suitable for land clearing, but it is essential that full use be made of the dead weight of the tractor, its drawbar pull and the leverage exerted by making a high hitch on the tree and a luw hitch on the tractor. Other forms of power such as steam tackle, gyro-tillers and bulldozers can also do most valuable work, if the size of the job justifies the use of expensive equipment. Explosives, particularly gelignite, offer a simple means of removing tree stumps and hedges; full details are given in the bulletin as to how they should be employed. Farmers requiring further information or help are recommended to get in touch with the machinery sections of the county war agricultural committees, who are in possession of the necessary tractors and employ full-time machinery officers to organize the equipment.

\section{School Science Teaching}

THE recent issue of the School Science Review (No. 92, Nov. 1942) contains an interesting article, "School Science Teaching after the War", by Mr. E. T. Harris. Mr. Harris points out that science teaching before the War was greatly affected by economic and social conditions which, in some cases, created a hostile attitude. But now, due to its contribution to the war effort, science is valued and appreciated. The changed social conditions likely to prevail after the War should give impetus to the modern movement to stress the applications of science, but the principles should not be omitted. ". . . Science is a social phenomenon, and is only to be understood in relation to the human society in which it has developed and is developing. Its principles and its applications are closely interrelated aspects of the same social phenomenon, and they must be studied in conjunction." In discussing how this principle may be applied in teaching, Mr. Harris cites the introduction of general science and the greater attention which biology is receiving nowadays (see Nature, 149, 456; April 25, 1942). There are two aspects to the study of science, (1) its historical and logical development and its social uses, and (2) its application to the pupil's life-his home, body, food, etc. Later in the science course should come a broadening of these early ideas, so that science is regarded as a struggle of mankind to master Nature for knowledge, power, and freedom.

\section{A New Universal Bevel Protractor}

Messrs. E. R. WATtS \& SoN, LTD., 123 Camberwell Road, London, S.E.5, have designed and introduced a new type of bevel gauge which should prove a most valuable tool in the engineering workshop for the convenient and accurate measurement of angles. The instrument consists essentially of two straightedges hinged together by means of the protractor head and capable of being set at any desired angle. The principal feature of this bevel gauge is the circular scale, which is divided accurately on a glass annulus mounted inside the head. The graduations on this scale are read by means of a high-power magnifier attached to the head and giving a wide field of view. The scale is most conveniently observed by looking through the eyepiece when the instrument is held in front of a source of artificial light, and under these conditions angles can be measured to within one twelfth of a degree. The straight-edges or blades are made of hardened steel and one of them is capable of sliding, an arrangement which greatly extends the range of the instrument, and two sizes of blade are provided-6 in. and $12 \mathrm{in.}$ The sliding blade is secured by an eccentric operated by a lever extending from the centre. When fitted with the short sliding blade, the dimensions of the gauge, closed, are $6 \frac{1}{2}$ in. $\times 2 \frac{8}{8}$ in. $\times 1 \frac{8}{4}$ in. and its accuracy in measurement is 5 minutes of angle. The blades are secured in angular position by means of a knurled ring concentric with and surrounding the protractor head so that, in all respects, this tool lends itself to rapid and convenient operation.

\section{The Royal Observatory, Cape of Good Hope}

ThE 1941 report of H.M. Astronomer at the Cape, though showing only too clearly the impact of the War on South African astronomy, contains much of interest. The reversible transit circle has been fairly fully employed in making 7,234 transit observa. tions, including fifty-seven of the moon, which were undertaken in view of the fact that lunar observations have perforce been dropped from the restricted programmes of many European observatories. With the Victoria telescope the stellar parallax programme has been continued, 2,642 plates having been secured during the year. A new determination of the parallax of Proxima Centauri, the star closest to the sun, gives $0.763^{\prime \prime} \pm 0.007^{\prime \prime}$, in good agreement with the previously accepted figure of $0.762^{\prime \prime} \pm 0 \cdot 005^{\prime \prime}$; this should be compared with the value $0.756^{\prime \prime} \pm 0.007^{\prime \prime}$ for $\alpha$ Centauri. It is interesting to note that during recent years the number of plates used for a parallax determination has increased to thirty, taken over three years or more: this change is fully in accord with the experience gained in the cloudier weather (but better seeing) at Greenwich.

The photoheliograph record of the sun's disc has suffered somewhat from the shortage of fine-grain plates, but a record, either on lantern plates or faster emulsions, was obtained on 311 days. Observations of occultations by the moon indicate a correction of $0 \cdot 77^{\prime \prime}$ to its ephemeris longitude, which is of course based on Brown's Tables. This correction is expected to reach zero in 1943 . Cometary 